\title{
Erratum to: The Effects of Nandrolone Decanoate Along with Prolonged Low-Intensity Exercise on Susceptibility to Ventricular Arrhythmias
}

Fateme Binayi $^{1,2} \cdot$ Siyavash Joukar $^{1,2} \cdot$ Hamid Najafipour $^{2,3}$. $^{1,2}$. $^{1,2}$ Farzane Abdollahi $^{1,2} \cdot$ Yaser Mami $^{1}$
Abdolah Karimi $^{12} \cdot$

Published online: 7 April 2015

(C) Springer Science+Business Media New York 2015

\section{Erratum to: Cardiovasc Toxicol}

\section{DOI 10.1007/s12012-015-9313-3}

Unfortunately, the first name of the fourth author was published incorrectly in the original article. It has been corrected with this erratum.

The author regrets the error caused.

The online version of the original article can be found under doi:10.1007/s12012-015-9313-3.

Siyavash Joukar

sjokar@gmail.com; jokar@kmu.ac.ir

1 Physiology Research Center, Institute of

Neuropharmacology, Kerman University of Medical

Sciences, Kerman, Iran

2 Department of Physiology and Pharmacology, School of Medicine, Kerman University of Medical Sciences, P.O.Box 7616914115, Kerman, Iran

3 Cardiovascular Research Center, Institute of Basic and Clinical Physiology Sciences, Kerman University of Medical Sciences, Kerman, Iran 